\title{
STUDIES OF INTESTINAL DIGESTION AND ABSORPTION IN THE HUMAN ${ }^{1}$
}

\author{
By B. BORGSTROM, A. DAHLQVIST, G. LUNDH, AND J. SJOVALL \\ (From the Swedish Medical Research Council, Unit for Metabolic Studies, and the Department \\ of Physiological Chemistry, University of Lund, Lund, Sweden)
}

(Submitted for publication May 1, 1957; accepted May 23, 1957)

Our knowledge of the processes underlying the normal digestion and absorption in the human small intestine is incomplete in spite of a considerable volume of research devoted to this subject (1-3).

While balance studies and blood analysis of absorbed material only give indirect information in this respect, more definite knowledge of the digestion and absorption processes must include studies of the composition of the intestinal content of different parts of the intestine during digestion and absorption. Various techniques using intubation of the human intestinal tract $(4,5)$ have also provided results in this direction and have given some information about factors such as $\mathrm{pH}(6,7)$, enzyme concentrations (6), and composition of ingested foodstuffs (8). Such information per se, however, is incomplete if it does not make it possible to calculate the extent of absorption at different levels. Such quantitative data have hitherto been obtained in special cases only by collecting intestinal content from segments isolated between balloons or proximal to occluding balloons $(3,9,10)$ with techniques which are not generally applicable and which in many cases are physiologically unsuitable.

In the study presented here we have aimed at an analysis of the digestion and absorption processes in the small intestine of normal adult human subjects. Sampling at different levels of the intestinal tract after feeding a well-balanced liquid test meal has been effected with the transintestinal intubation technique as described by Blankenhorn, Hirsch, and Ahrens (5). This technique, which utilizes intubation with a polyvinyl tubing (inner diameter, $2.1 \mathrm{~mm}$.), allows sampling at any desired level of the gut under conditions very closely resembling the physiological state. To get quantitative figures as to the sites and extent of absorp-

\footnotetext{
1 This investigation was generously supported by the Swedish Medical Research Council.
}

tion of various substances included in the test meal, a reference substance, polyethylenglycol, with a molecular weight of 3000 to 3700 , has been incorporated into the test meal. Although highly soluble in water, this substance is not absorbed or decomposed in the intestinal tract.

It has thus been possible to follow the dilution of the meal at different levels and to follow the absorption of the various components of the foodstuffs over the length of the human small intestine. Simultaneous analysis of the intestinal content as to concentration of foodstuffs and their digestion product, different bile constituents, enzymes, and $\mathrm{pH}$ has given information about the milieu of digestion from which the absorption takes place in the normal human being.

\section{MATERIAL AND METHODS}

The material includes experiments on six human subjects between 16 and 40 years of age: two female and four males, without any known gastrointestinal disorders.

The subjects were intubated according to the principles of Blankenhorn, Hirsch, and Ahrens (5) using a polyvinyl tubing (inner diameter, $2.1 \mathrm{~mm}$.), ${ }^{2}$ and sampling was generally started when the tube had passed the entire gastrointestinal tract. Sampling was generally attempted from both the oral and anal end of the tubing from perforations on the tubing located 50 to $100 \mathrm{~cm}$. apart and separated by a closed segment. In some cases sampling from the anal end was difficult or impossible since no free flow could be obtained. Altogether 16 successful experiments were performed on these subjects comprising 13 oral and 8 anal samplings. The test meal was usually given in the morning and intestinal content collected over a four-hour period. When the upper sampling was made from the duodenum or the first part of the jejunum two half-hour samples were taken during the first hour; later on and at lower levels hourly samples were taken. Sampling at levels lower than $300 \mathrm{~cm}$. from the nose was only successful in one case.

When it appeared from the studies of these six subjects that the major site of the absorption of the food-

\footnotetext{
2 The tubing was generously supplied by the Pharmaseal Laboratories, Glendale, California.
} 
stuffs was the distal duodenum and the first part of the jejunum six additional normal adults were studied. These subjects were intubated in the morning and given the test meal when the locus of aspiration had reached 70 to $125 \mathrm{~cm}$. from the nose. In these cases 10 -minute samples were taken during the first hour after the test meal and thereafter hourly samples were taken.

Usually the tubing moved slowly downwards during the sampling period and the distance from the nose to the site of aspiration for each sample is given as the mean value between the position at the beginning and the end of the sampling period. The position of the sampling area over the length of the intestine is given in $\mathrm{cm}$. from the nose. To localize this level, $\mathrm{X}$-rays were taken in some cases after injection of radio-opaque solution into the tubing. No attempts were made to localize exactly the position of the pylorus, ligament of Treitz, or the ileocecal valve. The variations in the position of these points have recently been reported by Hirsch, Ahrens, and Blankenhorn (11), and the arrows on the figures are calculated from their figures. They found the distance from nose to pylorus to be around $65 \mathrm{~cm}$.; from nose to ligament of Treitz to be around $90 \mathrm{~cm}$; and from nose to ileocecal valve to be around $350 \mathrm{~cm}$.

The test subjects were sitting in a chair during the collection period and the samples were collected in flasks chilled with crushed ice. At the beginning of the experiment the tubing was filled with water and flow was maintained by siphonage with the end of the tubing at floor level.

Test meal. The test meal given was a balanced liquid formula essentially with the composition given by Ahrens, Dole, and Blankenhorn (12). It consisted of a homogenized mixture of fat, protein, and carbohydrate, the distribution of calories being 40,15 , and 45 , respectively. Included in the test meal is also polyethylenglycol (PEG), serving as an indicator of the test meal, and radioiodinated human serum albumin (RIHSA) serving as an indicator of the food protein. The composition of the test meal is given in Table I. Of this liquid formula 500 ml. was taken orally during the first 10 to 15 minutes of each experiment. The caloric content of the test meal is 1.25 calories per $\mathrm{ml}$.

TABLE I

COMPOSITION OF TESTMEAL

\begin{tabular}{lcccc} 
& 9 & FAT & $\begin{array}{c}\text { CARBOHY- } \\
\text { DRATE }\end{array}$ & PROTEN \\
CORN OIL & 74 & 76 & - & - \\
SKIM MILK POWDER & 126 & 0.5 & 50 & 63 \\
DEXTROSE & 138 & - & 138 & - \\
PEG. & 5 & - & - & - \\
RIHSA & 1 & $\sim 5 \mu \mathrm{CI} \mathrm{I}^{131}$ & & 1 \\
WATER & 1000 & 74.5 & 188 & 66 \\
\cline { 2 - 5 } & & & & 50
\end{tabular}

Methods of analysis. Polyethylenglycol (PEG) ${ }^{8}$ concentrations were determined essentially according to Hydén (13).

Non-phospholipid fat was determined by weight after extraction of 5 to $10 \mathrm{ml}$. of the samples (acidified with hydrochloric acid) with a system containing equal parts of ethanol, diethyl ether, heptane and water as described by Ahrens and Borgström (8). In this way neutral fat and free fatty acids are obtained free from bile acids, amino acids, carbohydrate and salt. Less then five per cent of the total phospholipids present in the intestinal content is extracted with this method.

Lipid phosphorous was determined after extraction with 10 volumes of a mixture containing ethanol and acetone in equal volumes according to the Fiske and Subbarow method as used by Brante (14).

Free fatty acids were determined on the lipid extract by titration with $0.1-\mathrm{N} \mathrm{NaOH}$ using thymol blue as indicator.

Bile acids were determined with the method described by Sjövall (15). Optical density at $400 \mathrm{~m} \mu$ was measured in a 1-cm. cell on the supernatant after precipitation of the proteins with ten volumes of ethanol.

Glucose in the intestinal content was determined by a modification of the method described by Sumner (16) using 3,5-dinitrosalicylic acid as reagent.

Amylase was determined by the method of Meyer, Noelting, and Bernfeld (17). The amylase activity is expressed as milligrams of maltose liberated in three minutes by $1 \mathrm{ml}$. of the sample at $25^{\circ} \mathrm{C}$.

Sucrase activity was assayed according to a modification of the method of Sumner (18); the activity is given as milligrams of invert sugar produced in one hour by $1 \mathrm{ml}$. of the sample at $25^{\circ} \mathrm{C}$.

Lipase was assayed with a spectrophotometric method using a triolein emulsion as substrate (19).

Trypsin and chymotrypsin were determined spectrophotometrically with a modification of the method described by Schwert and Takenaka (20), using bensoylarginine ethyl ester and tyrosine ethyl ester, respectively, as substrates (21).

Assay of $I^{112}$-activity was made in a well-type scintillation counter, $10^{4}$ counts were counted on each sample. To get an estimation of the extent of hydrolysis of the protein we have determined the $I^{m}$-activity in the supernatant after phosphotungstic acid precipitation of the intestinal content (equal volumes of intestinal content, 5 per cent phosphotungstic acid and water) (22). One subject was fed a test meal containing approximately 10 microcuries ${ }^{14} \mathrm{C}$-triolein. The ${ }^{14} \mathrm{C}$ activity was determined on the total fatty acids of each fraction with a conventional flow counter.

The percentage absorption of fat, carbohydrate and protein at a given level was calculated from the relation of the amount of these substances to PEG concentration in the test meal and the same relationship in.

${ }^{3}$ The polyethylenglycol was obtained from Mo and Domsjö A.B., Sweden, under the name of "Polyglykol A 4000." 
the collected samples. In the case of protein, the total amount of radioactivity in the intestinal content was considered to be protein bound in these calculations. $p H$ values were determined with a glass electrode as soon as possible after the collection of the samples. In some cases continuous recording of $\mathrm{pH}$ was undertaken with the electrodes built into a chamber of $1.5 \mathrm{ml}$. volume through which the intestinal content passed. The $I^{121}$ labelled human serum albumin (RIHSA) was purchased from The Radiochemical Centre, Amersham, England.

\section{RESULTS AND DISCUSSION}

\section{The use of $P E G$ as a reference substance}

In 1953, Sperber, Hydén, and Ekman (23) reported the use of PEG as a reference substance in digestion studies. They used it in a study of ruminant digestion in the sheep and found it not to be absorbed or destroyed to any considerable extent in the alimentary tract and could recover more than 90 per cent in the feces. The behavior of different polyethylenglycols in the animal and human body had earlier been extensively studied by Shaffer, Critchfield, and Nair $(24,25)$ in connection with the introduction of these substances for pharmaceutical use (carbowax compounds). These authors (24) concluded that the higher polyethylenglycols are not absorbed after oral dosage in rat or man. Solid polyethylenglycols have also been reported suitable for use as reference substance for the estimation of fecal output in the cow (26).

The solid polyethylenglycols with a molecular weight of 3000 to 3700 used by Sperber, Hydén, and Ekman (23) and Corbett, Miller, Clarke, and Florence (26), therefore, seemed to be well documented for use as reference substance in studies of the digestion and absorption of water soluble substances in the human.4 Replicate samples taken from the same freshly drawn intestinal content gave constant ratios of fat to PEG. It, therefore, seems justifiable to use the watersoluble PEG as a reference substance also for fat when the latter is present in the test meal in a finely emulsified form.

\section{Recovery of test meal from the tube}

The sampling technique used in this investigation does not aim at a complete recovery of the

4 In two experiments a patient with ileostomy after total colectomy was fed the test meal and 103 and 95 per cent of the PEG recovered in the intestinal contents collected for 48 hours. intestinal content that passes a certain level. The amount of test meal contained in each sample obtained from the tubing can instead be calculated from the concentration therein of the reference substance (PEG) included in the test meal. If the samples obtained through the nasal end of the tubing from the six persons subjected to transintestinal intubation are considered, a fairly constant proportion of the test meal, as a mean $22.6 \pm$ 2.2 per cent, passed out through the tube during the four-hour sampling period. These figures include samples collected on levels from the duodenum down to $215 \mathrm{~cm}$. from the nose. The distribution of the test meal recovered from the tube, as calculated from the PEG values over the different hourly collection periods in the above experiments, was found to be $29.5,35.0,23.8$, and 11.7 per cent of the total amount recovered over the four-hour periods. Thus, the $500 \mathrm{ml}$. of test meal fed to these subjects are delivered from the stomach over a four-hour period, with the largest portion during the second hour. At levels lower than $150 \mathrm{~cm}$. from the nose (distal jejunum), the first hour samples usually did not contain any appreciable amount of test meal, indicating that the passage of the meal down the intestine is rather slow normally. When sampling from the duodenum and the first part of the jejunum, we generally observed that the flow ceased during the fourth hour, indicating that the stomach was empty at that time.

\section{Concentration in intestinal content of $P E G$}

Figure 1 shows the concentration of the reference substance in the samples collected at different levels. The general trend is a three- to fivefold dilution of the test meal in the duodenum followed by a concentration further down the small intestine. At levels below $150 \mathrm{~cm}$. from the nose we will find both very high and very low figures. The reason for the large differences found at these low levels will probably be found in the fact that the recovery through the tube of samples containing test meal is more by chance due to the small volume of viscous content passing. In some cases very low PEG values are found in samples obviously mostly representing intestinal secretion.

From the PEG values in the duodenum it can be calculated that the 500-ml. test meal during its pas- 


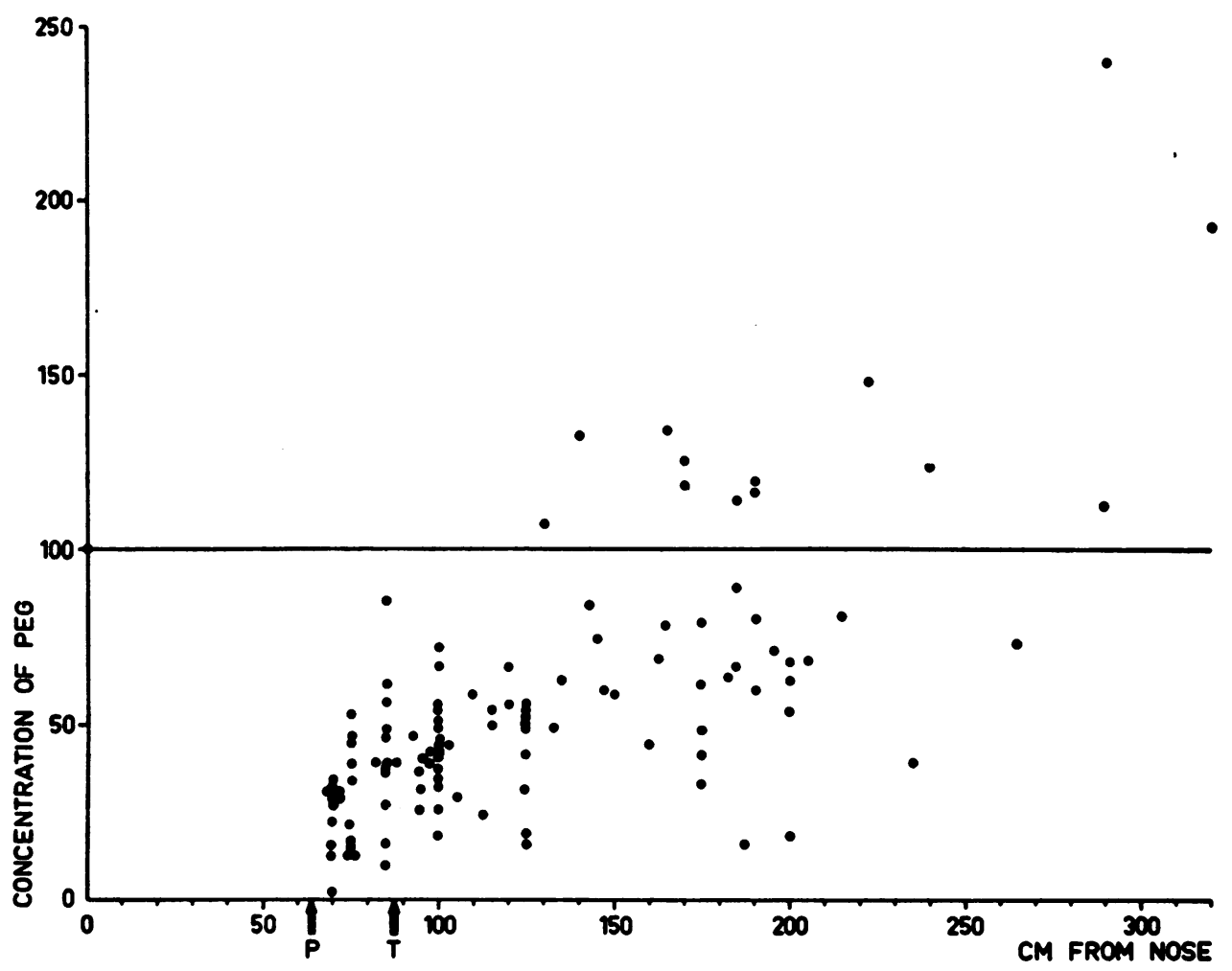

Fig. 1. Concentration of Polyethylenglycol (PEG) in Intestinal Content Collected at Different Levels of the Small Intestine After Fending 500-Gm. Test Meal

Concentration of PEG in the test meal equals 100.

sage through the duodenum is diluted to a volume of 1,500 to $2,500 \mathrm{ml}$.

\section{Absorption of fat, glucose and protein}

The presence in the test meal of a substance that is not absorbed nor digested makes it possible for the first time to calculate the absorption curves over the length of the human small intestine of the foodstuffs included in the meal. These curves for fat, glucose and protein are seen in Figure 2. It is seen that the absorption of these substances begins already in the distal part of the duodenum and is generally completed in the first 50 to 100 $\mathrm{cm}$. of the jejunum, a little higher up for fat than for glucose and protein. In the lower part of the small intestine the glucose concentration reaches zero while there are always some substances present in the intestinal content at all levels which are extractable with fat solvents. That this fat is mainly of dietary origin is shown from the experiment in which ${ }^{14} \mathrm{C}$-triolein was included in the fat of the test meal. In this subject intestinal con- tent was collected at a level of 190 to $200 \mathrm{~cm}$. from the nose during a four-hour period following the test meal. The lipid content of the four hourly samples was 5.1, 3.0, 6.9 and $3.1 \mathrm{mg}$. per ml. intestinal content with specific activities of $110,71,94$ and 79 per cent of that of the fat of the test meal.

Studies of the digestion and absorption of proteins are complicated by the difficulty of differentiating between food protein and the rather large quantities of endogeneous protein contained in the secretions to the intestinal tract (27). To indicate the food protein we have added radioiodinated human serum albumin (RIHSA) to the test meal. Using filter-paper chromatography we have found that in various samples of intestinal content collected in connection with a test meal containing RIHSA less than 10 per cent of the $I^{131}$ activity is in the form of inorganic iodine. Furthermore, Lavik, Mattews, Buckaloo, Lemm, Spector, and Friedell (28) have found that at the most 12 per cent of $\mathrm{I}^{131}$ bound to casein was liberated as 

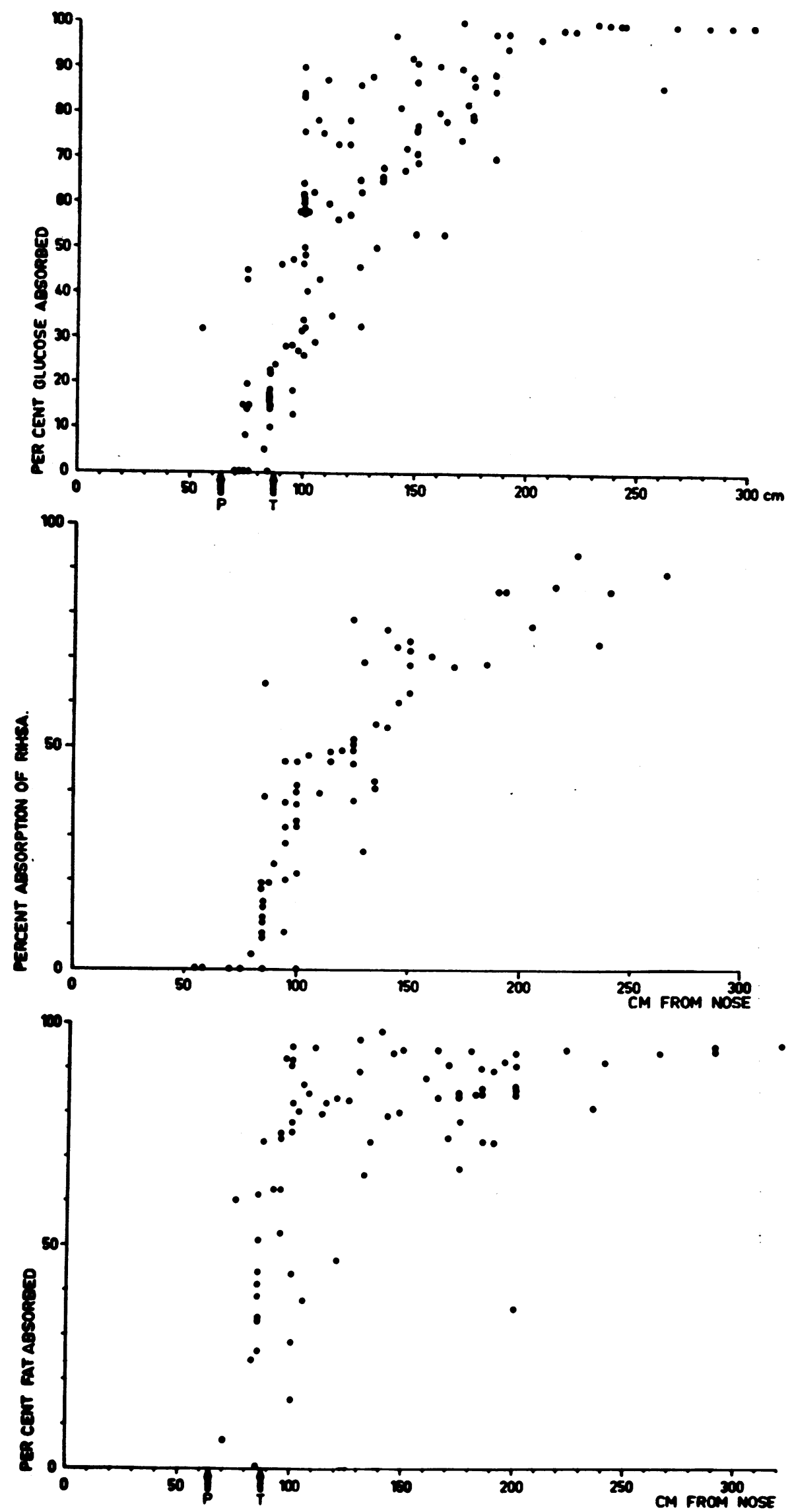

Fig. 2. Absorption Curves for Fat, Glucose (Plus Lactose) and Protein as IndiCated by I Im Over the Length of the Human Small Intestine 
inorganic iodine on incubation with intestinal juice from dog during a two-hour period. It therefore seems feasible to use RIHSA as an indicator of food protein and, consequently, when values for protein absorption are given, they have been calculated on the amounts of $\mathrm{I}^{181}$ activity in the sample.

The absorption of protein as indicated by RIHSA does not exceed 80 to 90 per cent, even at the lowest levels of the small intestine. These calculations cannot be influenced by endogeneous proteins and therefore indicate that the protein absorption in the small intestine is less complete than the absorption of glucose and fat. As, however, the fecal excretion of radioiodine in these cases and in other investigations (28) is very low, it is apparent that a certain breakdown of proteins must occur in the large intestine. Studies of protein absorption using ${ }^{15} \mathrm{~N}$ as a label in healthy human beings has also shown a mean protein absorption around 90 per cent (29).

As part of the carbohydrate in the test meal is lactose (around 25 per cent) and the lactose is determined with the glucose, we have made a few experiments in which lactose was the only carbo- hydrate in the test meal in amount corresponding to the amount of lactose plus glucose in the other experiments. Figure 3 shows that lactose is absorbed at the same level as is glucose.

The extent of absorption recorded is more dependent on the location of sampling than on the time elapsed after the ingestion of the test meal. In the upper part of the small intestine the extent of absorption, however, is low during the first halfhour of the digestion period.

The anatomical site of absorption of fat over the length of the human small intestine determined in this investigation is in accord with the general observations male in dogs by Bernard (30) onehundred years ago and the recent results obtained by Turner (31), also in dogs, studying the incorporation of fed $I^{181}$-labelled triolein in the intestinal mucosa during absorption. The conclusion that the distal small intestine is the major site for fat absorption reached by Kremen, Linner, and Nelson (32) and Benson, Chandler, Vansteenhuyse and Gagnon (33) working with dogs and rats, respectively, is at variance with the above results. In rats it has been shown that glucose is absorbed in the first part of the small intestine

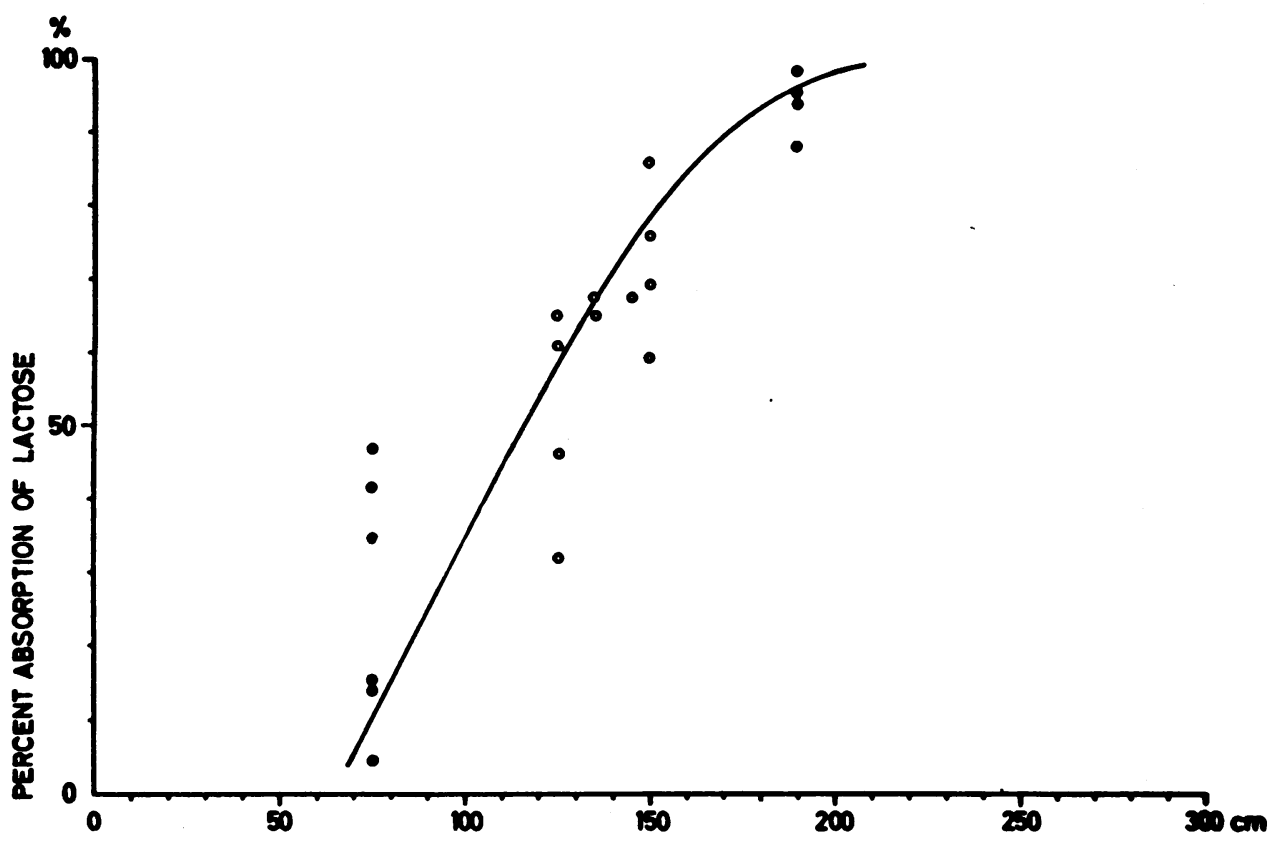

Fig. 3. Extent of Absorption of Lactose (O) Over the Length of the Human Syalt Intestine Compared with the Absorption Curve for Glucose (๑) in the Same Subject in Different Experiments

Solid line represents absorption curve for glucose drawn from Figure 2. 

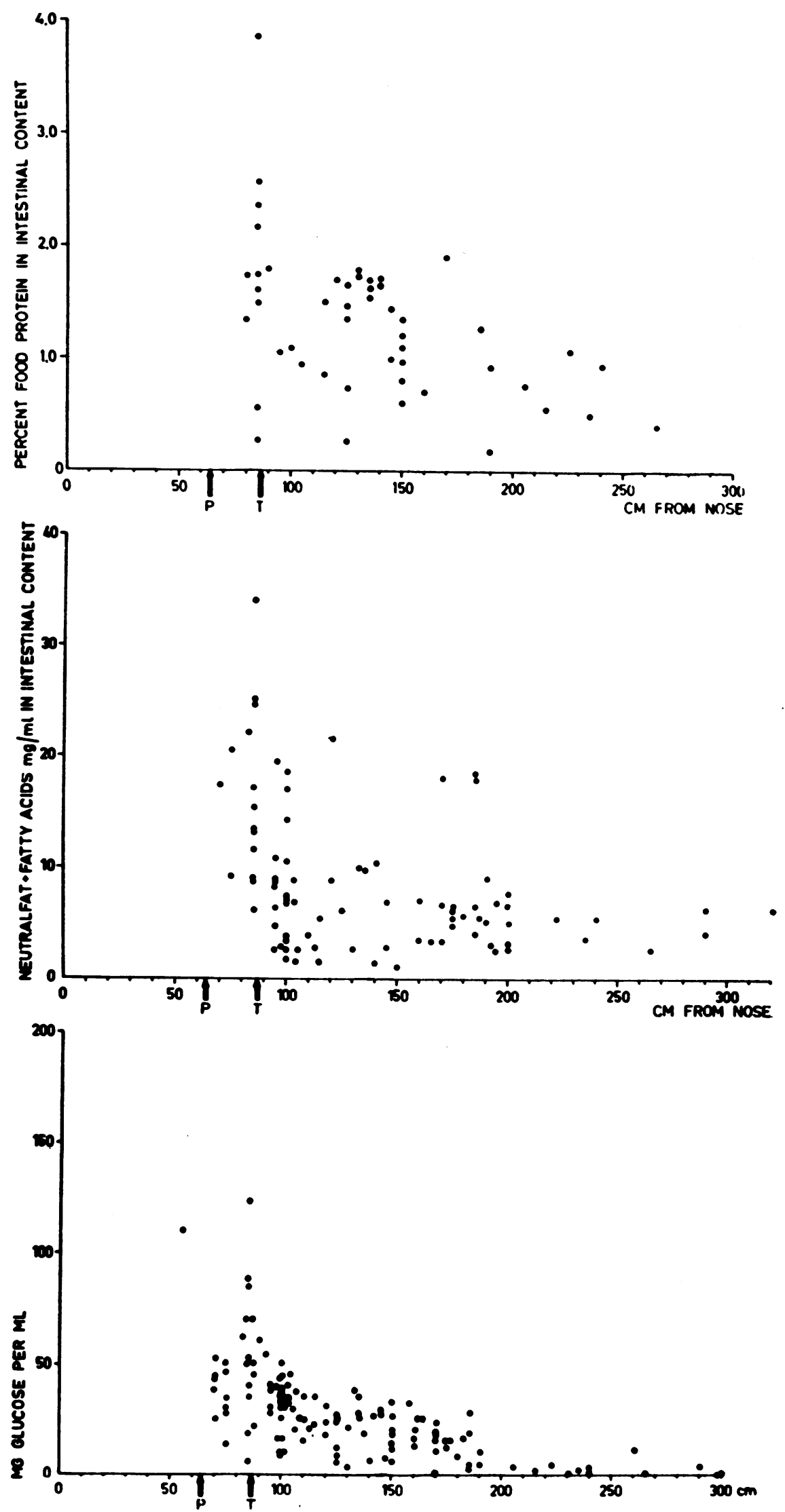

Fig. 4. Concentrations of Non-Phospholipid Fat, Glucose and Protein as. Calculated From the Total I ${ }^{13}$ Activity at Different levels of the Human Small Intestine After Feeding of 500-Gm. Test Meal 


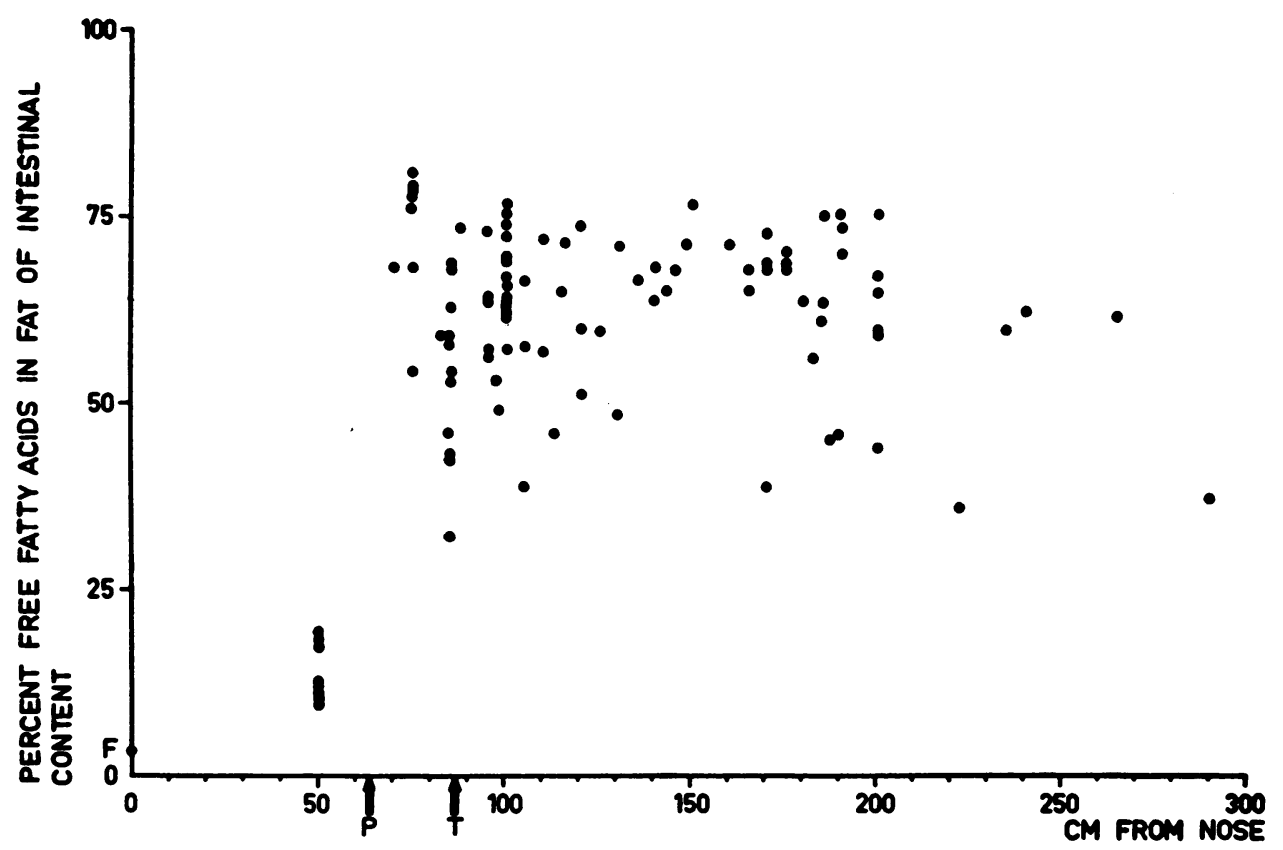

Fig. 5. Per Cent free fatty Acids found in the Non-Phospholipid Fat Recovered from the Intestinal Content at Different Levels of the Human Small Intestine During Digestion of 500-Gm. Test Meal

(34) and that most of the protein absorption takes place in the duodenum and upper part of the jejunum, but even to some extent in the colon (35).

\section{Concentration of fat, glucose and protein in the intestinal content}

The concentrations of non-phospholipid fat, glucose and protein as indicated by the labelled serum albumin in the intestinal content at different levels are seen in Figure 4. It is apparent that a rapid dilution has occurred in the duodenum which in combination with the absorption that has already started here gives figures for concentration of fat and protein that are around 10 to $20 \mathrm{mg}$. per $\mathrm{ml}$. and for glucose less than $50 \mathrm{mg}$. per ml., compared to 60 and $150 \mathrm{mg}$. per $\mathrm{ml}$., respectively, in the test meal. The concentration of glucose in the duodenum is thus in accord with earlier results $(36,37)$, practically never over that of an isotonic solution. The percentage of free fatty acids in the non-phospholipid fat recovered from the intestinal content (Figure 5) is at all levels around 65 to 70 per cent. These figures are higher than those earlier reported for lipids recovered from intestinal contents from animals and humans fed non-emulsified fat in large quantities $(38,39,44)$. It seems very probable that the finely emulsified fat fed in this investigation favors a more rapid hydrolysis.

In two experiments in the present investigation content was sampled from the stomach at different times over a four-hour period after ingestion of the test meal. The lipids recovered from these samples generally contained 10 to 20 per cent free fatty acids as indicated in Figure 5 . It is not possible to say from the present experiments whether this gastric digestion of the corn oil of the test meal is effected by the so-called gastric lipase (40) or by the action of regurgitated pancreatic lipase. We can only conclude that the fat of the test meal is already hydrolyzed to an appreciable extent when reaching the duodenum.

The concentration of food protein in the intestinal juice can approximately be calculated through the total $\mathrm{I}^{131}$-activity in the samples (Figure 4). In spite of the increasing concentration of the intestinal content there is a steady decrease in concentration of food protein. The decrease in concentration of food protein is similar to that for the enzymatic activity. Nasset, Schwartz, and Weiss (27) have found gradually increasing amounts of total nitrogen in intestinal content of 
dogs from duodenum to ileum after a non-protein test meal, which they believe indicates an accumulation of digestive enzymes and other proteins contributed by the gastric, pancreatic and intestinal juices. Our results speak in favor of a parallel digestion and absorption of food protein and enzyme protein. Nasset, Schwartz, and Weiss (27) also have discussed the problem of the protein turnover in the digestive glands. With the technique used here, it might be possible to further investigate this problem.

The extent of hydrolysis of the food protein as indicated by $\mathrm{I}^{131}$-activity (equals per cent of total activity in the supernatant after precipitation with 5 per cent phosphotungstic acid) (22) is very low in the stomach, 10 to 15 per cent, but reaches very rapidly in duodenum values of 50 to 60 per cent. This extent of the hydrolysis is then rather constant in samples from lower levels. No effort has been made to analyze the composition of the hydrolyzed protein.

\section{Concentrations of enzyme in the intestinal content}

Of the enzymes known to be contained in the pancreatic juice we have determined lipase, trypsin, chymotrypsin and amylase. They approximately follow each other and in Figure 6 are seen the values obtained for trypsin and chymo- trypsin in the intestinal content collected at different levels of the small intestine. It is apparent that there exist wide variations in the concentrations of these enzymes over the length of the intestine if no consideration is taken to the time relationship. There is a general trend to a decrease in enzyme concentration the further down in the intestine the samples have been collected in spite of a concentration of the intestinal content in the same direction (see Figure 1). This fact must indicate that the enzymes are partly inactivated or autodigested in the lumen of the small intestine. Due to the progressive concentration of the intestinal content in the lower part of the intestine an appreciable enzyme concentration, however, is maintained over the length of the small intestine. If the enzyme-time relationship is studied in the upper part of the small intestine (Figure 7) it is seen that the pancreatic secretion is started 10 to 20 minutes after the ingestion of the test meal and then continues to flow as long as there is any food in the stomach. The decrease in enzyme concentration apparent during the latter part of the first hour and the most of the second hour is probably explained by dilution of the pancreatic juice with the test meal, the main part of which passes during this time.

To get some data on the site of production and

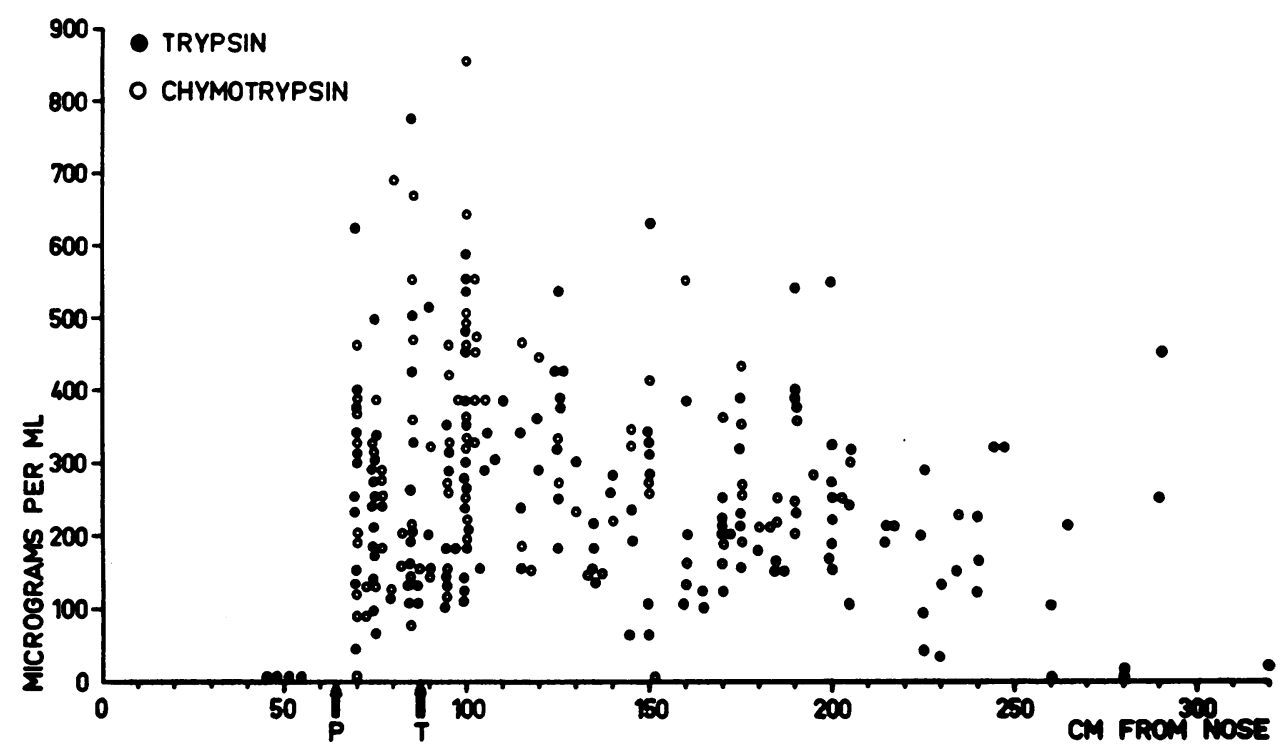

Fig. 6. Concentration of Trypsin and Chymotrypsin in Intestinal Content Collected at Different Levels of the Human Small Intestine After 500-Gm. Test Meal 


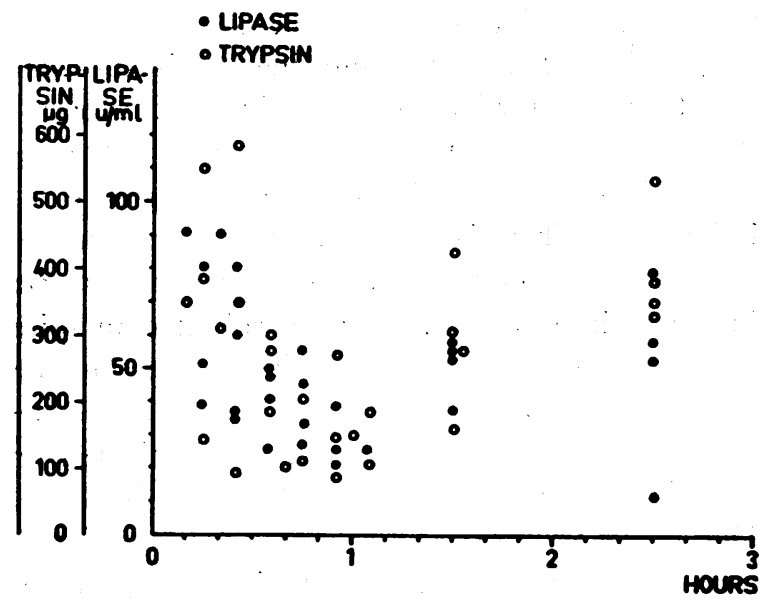

Fig. 7. Enzyme Tme Relationship for Trypsin and Lipase in the Intestinal Content from the Duodenum and the Proxmal Jejunum After Feeding 500-Gm. Test Meal to Normal Human Beings

enzymatic content of the so-called succus entericus we have determined the invertase activity of the intestinal content at different levels. These values are given in Figure 8 and show a course very different from that of the pancreatic enzymes. There is very little invertase activity in the duodenum and the proximal jejunum where the pancreatic enzymes have their maximum values. The invertase activity varies greatly in spite of the fact that this enzyme is fairly stable in vitro, and has maximum values at a level about $200 \mathrm{~cm}$. from the nose. If the activity of invertase and amylase in the intestinal content is compared it can be calculated that the amylase contained in $1 \mathrm{ml}$. intestinal content can digest around $5 \mathrm{Gm}$. starch per hour at $37^{\circ} \mathrm{C}$. while the corresponding figure for the invertase activity is less than $0.02 \mathrm{Gm}$. saccharose. Thus there is a great difference in activity per ml. of intestinal content and it is also apparent from the absorption curve shown in Figure 3 that a disaccharide as lactose is absorbed at a level of the small intestine where the disaccharide splitting enzymes are absent or have a low concentration. It should be added that other experiments (41) show that the lactase activity of intestinal content follows the same course as the invertase activity and is only about half of that

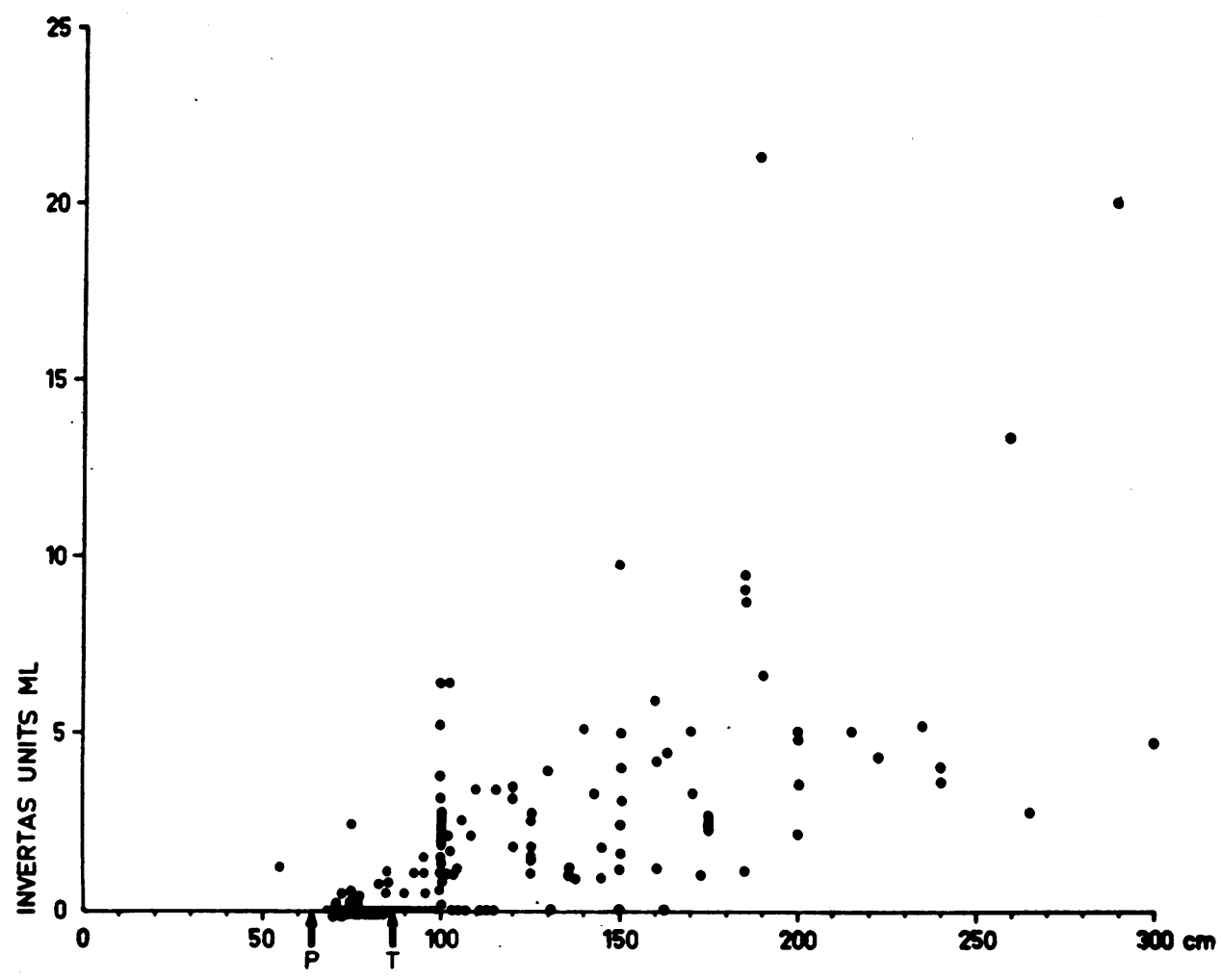

Fig. 8. Concentration of Invertase Over the Length of the Human Small Intestine After 500-GM. Test Meal 

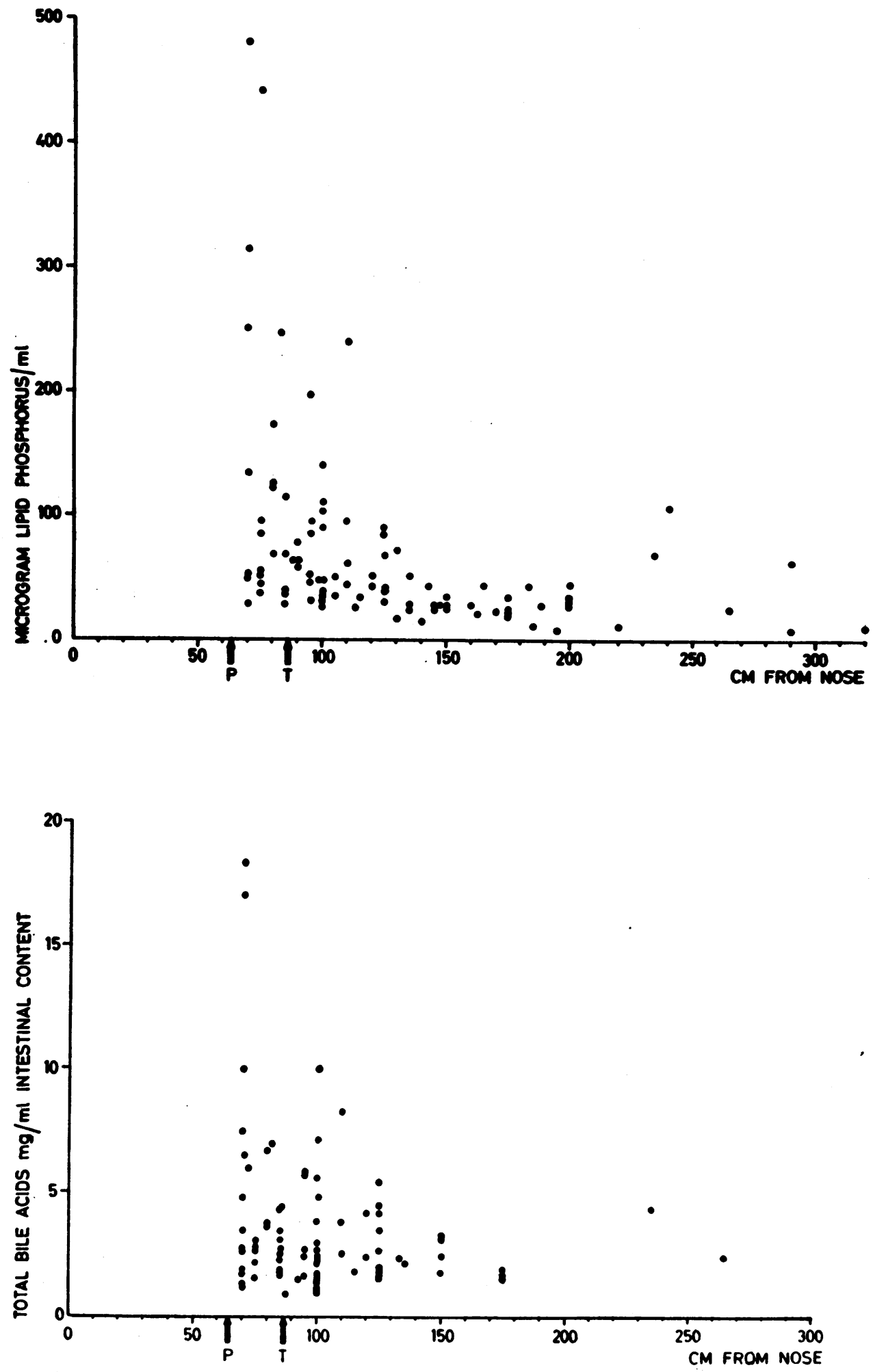

Fig. 9. Concentration of Total Bile Acids and Lipid Phosphorus in the Intestinal Content at Different Levels After Feeding of 500-Gm. Test Meal 

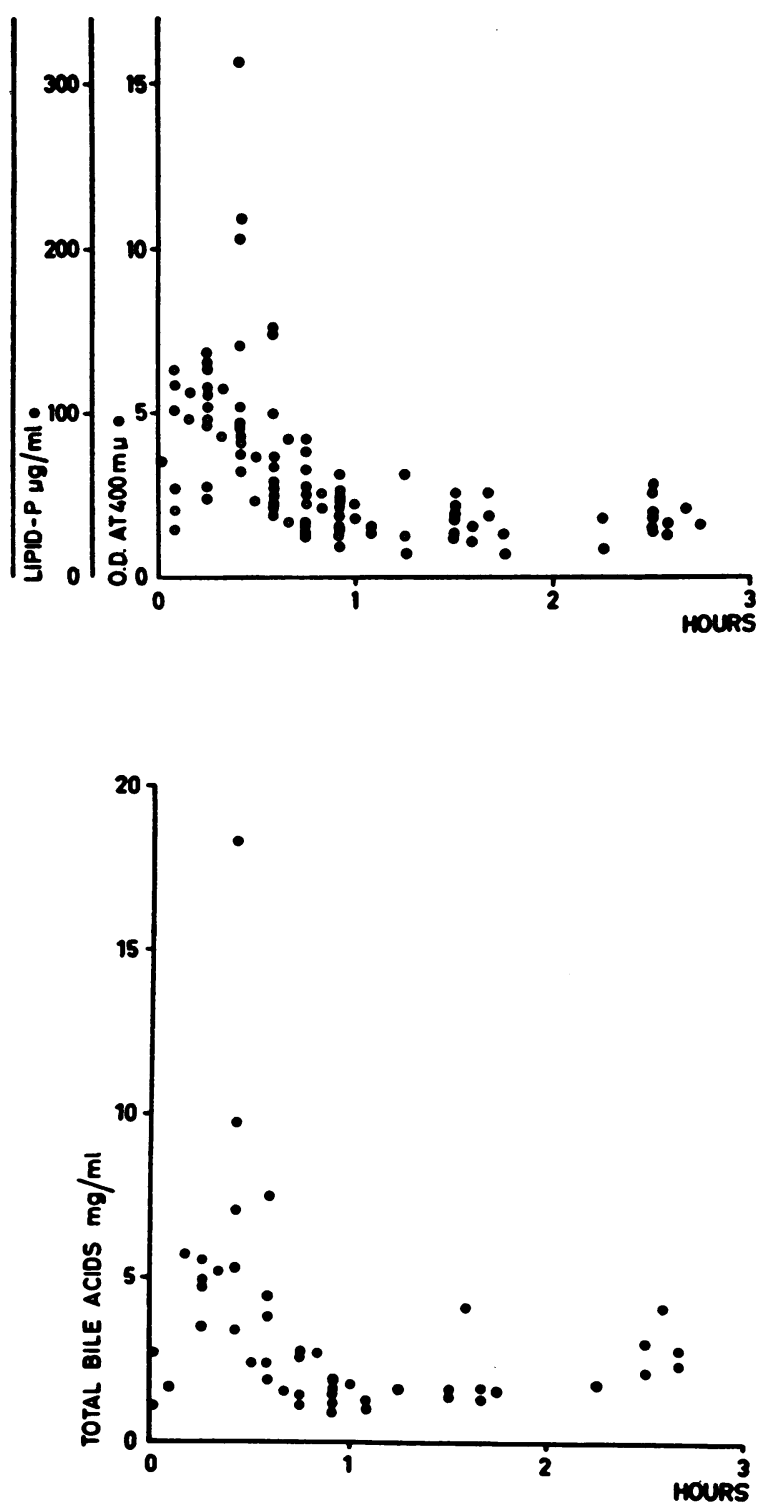

Fig. 10. Time Relationship for the Concentration of Bile Acids Lipid Phosphorus and for Optical DenSity at $400 \mathrm{M} \mu$ of the Intestinal Content Collected in the Duodenum and the Proximal Jejunum After the Feeding of 500-Gm. Test Meal

of the invertase activity. It is therefore tempting to draw the conclusion that the presence of disaccharide splitting enzymes in the succus entericus is of no importance for the absorption of the disaccharides, the action of these enzymes being confined to the intestinal cells. This opinion is in accord with the conclusions drawn by Cajori (42) in experiments on intestinal loops of dogs that sucrose and lactose are absorbed much more rapidly than would be predicted on the basis of the enzymatic activity of the intestinal juice. Based on a study on a comparison of the concentration of lactase in the intestinal content and in the mucosal cells Heilskov (43) has recently arrived at the opposite conclusion, i.e., the lactase is secreted to and acts in the intestinal content. It seems to us, however, that the data of Cajori and of this investigation are more relevant to the solution of the problem of the primary action of these enzymes.

\section{Bile constituents in the intestinal content}

Of the bile constituents in the intestinal content we have determined phospholipids as lipid phosphorus and bile salts. The concentration of these bile constituents in the intestinal content is high in the duodenum and the proximal jejunum (Figure 9), then decreases due to absorption and probably hydrolysis of the phospholipids. The phospholipids in the intestinal content after a test meal free of phospholipids are derived from the bile lecithin. In studies to be reported (44) it will be shown that this lipid phosphorus is present in the intestinal content chiefly as lysolecithin formed by the action of a lecithinase $\mathrm{A}$ in the pancreatic juice on the bile lecithin. The figures for bile acids are expressed as total free bile acids. All the bile acids, with the possible exception of trace amounts, occur conjugated with glycine and taurine, the ratio of glycine to taurine conjugates varying between 1.5 and 5 . A more complete report on the concentrations of the different bile acids will be given later.

Figure 10 shows the time course of the concentrations of the bile acids and lipid phosphorus in the duodenum and the upper jejunum. It is apparent that the gall bladder empties during the first half hour after the ingestion of the test meal. During this time we can see high concentrations of bile constituents in the upper part of the small intestine. Later on during the second and following hours and as long as we have any test meal in the stomach, the concentration of bile acids and phospholipids goes down to a lower and relatively constant value of 1 to $3 \mathrm{mg}$. per ml. of bile acids and around $0.5 \mathrm{mg}$. per ml. of phospholipid, chiefly as lysolecithin. As only about 30 per cent of the test meal is passing the duodenum during the first hour it is apparent that most of the meal is 
digested and absorbed from a milieu with the above composition. As we know the mean bile acid concentration in the intestinal content in the duodenum and the proximal jejunum during the digestion period is 204 to $330 \mathrm{mg}$. per $100 \mathrm{ml}$., and from the PEG values can calculate the dilution of the test meal, it is possible to get an approximate figure of 4 to $8 \mathrm{Gm}$. for the total amount of bile acids that passes the duodenum and is used for the digestion and absorption of the test meal. This is a minimum figure as the bile acids most likely start to be absorbed even while in the duodenum. When these figures are compared with the total circulating amount of bile acids in the human recently determined by isotope dilution by Lindstedt (45) to be 1.88 to $4.97 \mathrm{Gm}$. in eight experiments with a mean figure of $3.58 \mathrm{Gm}$., it is apparent that the bile salts are excreted to the intestine and absorbed about two times during the digestion and absorption of a meal of the kind given in these experiments. The total amount of phospholipids mixed with the test meal can correspondingly be calculated to be 0.75 to $1.5 \mathrm{Gm}$. as lysolecithin. Thus the $30 \mathrm{Gm}$. of triglycerides contained in the test meal are mixed in the intestine with approximately 20 per cent their weight of bile acids and 2.5 to 5 per cent of lysolecithin.

From Figure 10 it is seen that there is a very good parallelity between optical density at 400 $\mathrm{m} \mu$ of the intestinal content mainly due to the bile pigments and the concentration of bile acids and phospholipids in the duodenum and the proximal jejunum under the conditions of our experiments. Further down in the intestine when the bile acids and phospholipids are partly absorbed and the bile pigments concentrated large differences are seen in this relationship.

\section{$p H$ of the intestinal content}

Figure 11 includes $\mathrm{pH}$ values of the intestinal content at different levels of the small intestine. They increase slowly from values around six in the duodenum to figures at or close to eight in the lower ileum. These figures are essentially in accord with those earlier obtained from humans $(6,39)$. Figure 12 shows curves from direct continuous registration of $\mathrm{pH}$ in the duodenum and the proximal jejunum during the digestion and absorption of the test meal. Generally, very constant $\mathrm{pH}$ values around six are found in the duodenum, and the curve in Figure 12 is representative for most of the experiments performed.

The $\mathrm{pH}$ of the stomach content during the fourhour sampling period after ingestion of $500-\mathrm{Gm}$. test meal shows a decrease from around four to five during the first hour down to $\mathrm{pH}$ values around two during the fourth hour when the

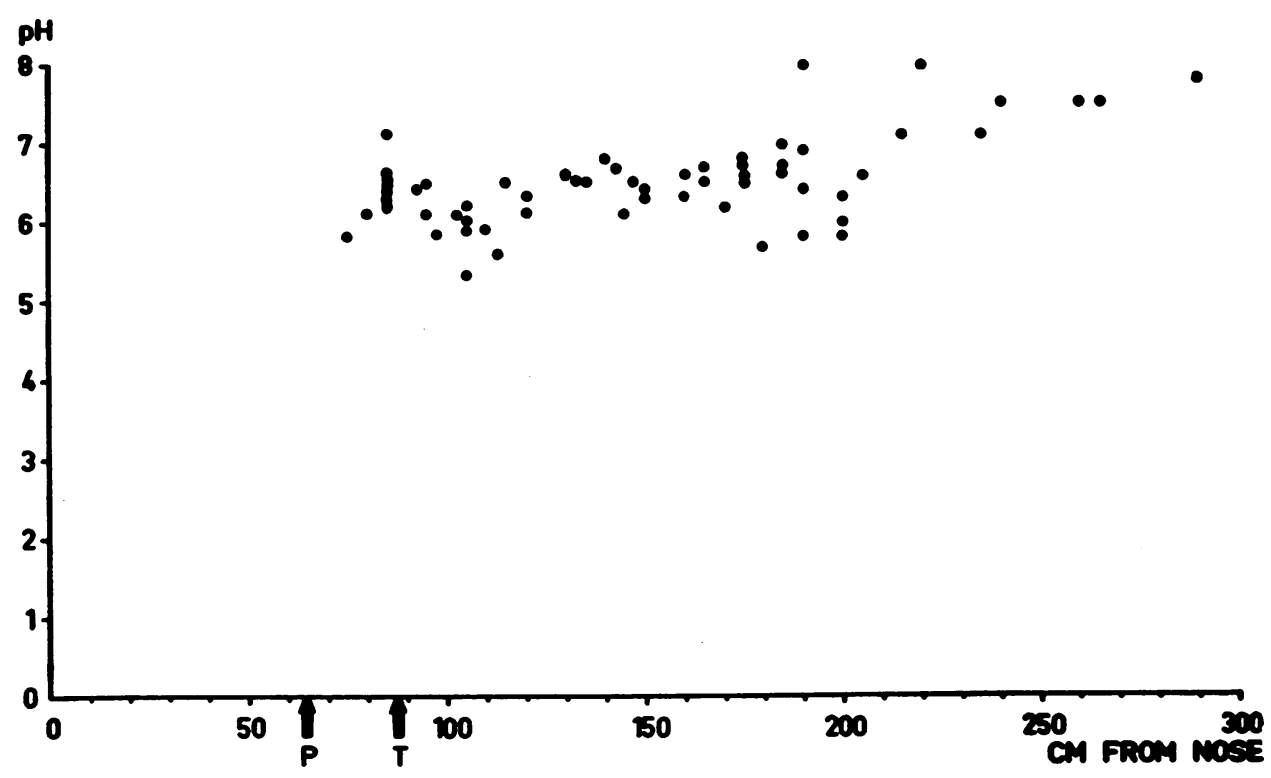

Fig. 11. pH of the Intestinal Content Collected at Different Levels of the Human Sycall Intestine After Feeding of 500-Gu. Test Meal 




Fig. 12. Continuous Registration of pH of Intestinal Content Flowing From a Tubing Draiming the Duodenum During Digestion of a 500-Gm. Test Meal

stomach starts to be empty. Apparently the proteins of the test meal effectively buffer the acid secretion of the stomach under the conditions of our experiments.

\section{CONCLUSIONS}

The intestinal digestion and absorption were studied in normal human beings, 16 to 40 years of age, subjected to intestinal intubation with a polyvinyl tubing (inner diameter, $2.1 \mathrm{~mm}$.), allowing sampling of intestinal content at apy level of the gastrointestinal tract.

The test subjects were fed a fluid test meal containing fat as corn oil, carbohydrate as glucose plus lactose, and protein as milk proteins in wellbalanced proportions. The test meal also contained a water soluble non-absorbable reference substance (PEG) to indicate the test meal and I'131-labelled human serum albumin (RIHSA) to indicate the food protein.

From the results obtained it was possible to draw the following conclusions:

1. The $500-\mathrm{Gm}$. test meal is delivered from the stomach to the duodenum in small portions over a four-hour period with a maximum amount during the second hour.

2. The test meal passes the duodenum diluted three to five times.

3. The absorption of fat, carbohydrate and protein begins in the duodenum and is completed in the proximal $100 \mathrm{~cm}$. of the jejunum, more proximal for fat than for carbohydrate and more proximal for carbohydrate than for protein. Fat in the form of corn oil is absorbed to 90 to 95 per cent and is not significantly diluted with endogenous fat in the small intestine; carbohydrate in the form of glucose plus lactose is absorbed to 100 per cent, and protein as indicated by RIHSA to 80 to 90 per cent.

4. The concentration in the intestinal content of enzymes contained in the pancreatic juice is highest in the duodenum and the proximal jejunum. Due to auto-digestion, the enzyme concentration decreases slowly in distal direction in spite of a progressive concentration in the same direction of the intestinal content. The result, however, is that a considerable concentration of enzymes is maintained over the length of the small intestine.

5. There seems to be reason to believe that the enzymes contained in the so-called succus entericus are of no or little importance for the intraluminar digestion and absorption. The major locus of action of these enzymes most probably is intracellular.

6. The gall bladder is emptied during the first 30 minutes after the test meal, giving rise to high concentrations of bile salts and phospholipid in the content of duodenum and proximal jejunum. In this way the bile constituents stored in the gall bladder are brought into circulation during the first part of the digestion period, the main part of the test meal being mixed with liver bile and digested and absorbed from a milieu with concentrations of bile acids around 1 to $3 \mathrm{mg}$. per $\mathrm{ml}$. and of phospholipid of around 0.5 to $1 \mathrm{mg}$. per ml. chiefly as lysolecithin. The total amount of bile acids mixed with the test meal has been calculated to 4 to $8 \mathrm{Gm}$., which are minimum figures. This means that the bile acid pool is circulated about two times during the digestion period.

7. The $\mathrm{pH}$ of the intestinal content during digestion in the duodenum is around six and increases slowly in distal direction to values up to 
eight. The $\mathrm{pH}$ in the duodenum and the jejunum is very constant during the digestion period.

\section{ACKNOWLEDGMENT}

The authors wish to express their gratitude to Mrs. Maj-Britt Nilsvik and Mrs. Berit Andersson for technical assistance.

\section{REFERENCES}

1. Verzár, F., and McDougall, E. J., Absorption from the Intestine. London, Longmans, Green and Co., 1936.

2. Miller, T. G., Intubation studies of the human small intestine. XXVI. A review of a ten year experience. Gastroenterology, 1944, 3, 141.

3. Cummins, A. J., Absorption of glucose and methionine from the human intestine; the influence of the glucose concentration in the blood and in the intestinal lumen. J. Clin. Invest., 1952, 31, 928.

4. Miller, T. G., Abbott, W. O., and Karr, W. G., Intubation studies of the human small intestine. VIII. Miscellaneous observations. Am. J. Digest. Dis., 1936-37, 3, 647.

5. Blankenhorn, D. H., Hirsch, J., and Ahrens, E. H., Jr., Transintestinal intubation: Technic for measurement of gut length and physiological sampling at known loci. Proc. Soc. Exper. Biol. \& Med., 1955, 88, 356.

6. Karr, W. G., and Abbott, W. O., Intubation studies of the human small intestine. IV. Chemical characteristics of the intestinal content in the fasting state and as influenced by the administration of acids or alkalies and of water. J. Clin. Invest., 1935, 14, 893.

7. Rovelstad, R. A., Continuously recorded in situ $\mathrm{pH}$ of gastric and duodenal contents in patients with and without duodenal ulcers. Gastroenterology, 1956, 31, 530.

8. Ahrens, E. H., Jr., and Borgström, B., Exchange of free fatty acids and glyceride fatty acids during fat digestion in the human intestine. J. Biol. Chem., 1956, 219, 665.

9. Nicholson, J. T. L., and Chornock, F. W., Intubation studies of the human small intestine. XXII. An improved technic for the study of absorption; its application to ascorbic acid. J. Clin. Invest., 1942, 21, 505.

10. Cummins, A. J., and Jussila, R., Comparison of glucose absorption rates in the upper and lower human small intestine. Gastroenterology, 1955, 29, 982.

11. Hirsch, J., Ahrens, E. H., Jr., and Blankenhorn, D. H., Measurement of the human intestinal length in vivo and some causes of variation. Gastroenterology, 1956, 31, 274.

12. Ahrens, E. H., Jr., Dole, V. P., and Blankenhorn, D. H., The use of orally-fed liquid formulas in metabolic studies. Am. J. Clin. Nutr., 1954, 2, 336.

13. Hydén, S., A turbidometric method for the determination of higher polyethylene glycols in biological materials. Ann. Agr. Coll. Sweden, 1955, 22, 139.

14. Brante, G., Studies on lipids in the nervous system with special reference to quantitative chemical determination and topical distribution. Acta physiol. Scandinav., 1949, Suppl. 63.

15. Sjövall, J., Quantitative determination of bile acids in human bile. Acta chem. Scandinav., 1956, 10, 1051.

16. Sumner, J. B., A more specific reagent for the determination of sugar in urine. J. Biol. Chem., 1925, 65, 393.

17. Meyer, K. H., Noelting, G., and Bernfeld, P., Recherches sur l'amidon XXXVII. Détermination du poids moleculaire de polysaccharides natureles par dosage colorimetrique. Helv. Chim. Acta., 1948, 31, 103.

18. Sumner, J. B., and Howell, S. F., A method for determination of saccharase activity. J. Biol. Chem., 1935, 108, 51.

19. Borgström, B., Determination of pancreatic lipase in human intestinal content. Scand. J. Lab. Clin. Med., 1957, In press.

20. Schwert, G. W., and Takenaka, Y., A spectrophotometric determination of trypsin and chymotrypsin. Biochim. et biophys. acta, 1955, 16, 570.

21. Lundh, G., Determination of trypsin and chymotrypsin in human intestinal content. Scand. J. Lab. Clin. Med., 1957, In press.

22. Hiller, A., and Van Slyke, D. D., A study of certain protein precipitants. J. Biol. Chem., 1922, 53, 253.

23. Sperber, I., Hydén, S., and Ekman, N. J., The use of polyethylene glycol as a reference substance in the study of ruminant digestion. Ann. Agr. Coll. Sweden, 1953, 20, 337.

24. Shaffer, C. B., and Critchfield, F. H., The absorption and excretion of the solid polyethylene glycols ("carbowax" compounds). J. Am. Pharm. A. (Scient. Ed.), 1947, 36, 152.

25. Shaffer, C. B., Critchfield, F. H., and Nair, J. H., The absorption and excretion of a liquid polyethylene glycol. J. Am. Pharm. A. (Scient. Ed.), $1950,39,340$.

26. Corbett, J. L., Miller, T. B., Clarke, E. W., and Florence, E., The use of polyethylene glycol as an inert reference substance for the estimation of faecal output. Proc. Nutrition Soc., 1956, 15, V.

27. Nasset, E. S., Schwartz, P., and Weiss, H. V., The digestion of proteins in vivo. J. Nutrition, 1955, $56,83$.

28. Lavik, P. S., Matthews, L. W., Buckaloo, G. W., Lemm, F. J., Spector, S., and Friedell, H. L., Use of $I^{2 m}$-labeled protein in the study of protein digestion and absorption in children with and without cystic fibrosis of the pancreas. Pediatrics, 1952, 10, 667. 
29. Sharp, G. S., Lassen, S., Shankman, S., Gebhardt, A. F., and Hazlet, J. W., Studies of protein absorption using nitrogen ${ }^{\text {ss }}$ as a tag. J. Nutrition, 1956, 58, 443.

30. Bernard, C., Mémoire sur le pancreas et sur la rôle du suc pancreatique dans les phénomènes digestifs, particulairement dans la digestion des matières grasses neutres. Paris, Ballière, 1856.

31. Turner, D. A., The absorption, transport and deposition of fat. Thesis, Washington, 1950.

32. Kremen, A. J., Linner, J. H., and Nelson, C. H., An experimental evaluation of the nutritional importance of proximal and distal small intestine. Ann. Surg., 1954, 140, 439.

33. Benson, J. A., Chandler, G. N., Vansteenhuyse, F. E., and Gagnon, J. O., Studies concerning the site of fat absorption in the small intestine of the rat. Gastroenterology, 1956, 30, 53.

34. Reynell, P. C., and Spray, G. H., The simultaneous measurement of absorption and transit in the gastro-intestinal tract of the rat. J. Physiol., 1956, 131, 452.

35. Schlüssel, H., and Sunder-Plassmann, L., Zur Lokalisation der Eiweissresorption im Magen-Darmtrakt. Tierexperimentelle Untersuchungen mit $\mathrm{S}^{23}$-Markiertem Hefeeiweiss. Klin. Wchnschr., 1953, 31, 545.
36. Karr, W. G., Abbott, W. O., Hoffman, O. D., and Miller, T. G., Intubation studies of the human small intestine. XIII. The concentration and movement of glucose solutions in the stomach and duodenum. Am. J. Med. Sci., 1940, 200, 524.

37. Abbott, W. O., Karr, W. G., Glenn, P. M., and Warren, R., Intubation studies of the human small intestine. XIV. The absorption of glucose from the duodenum. Am. J. Med. Sci., 1940, 200, 532.

38. Harris, R. S., Chamberlain, J. W., and Benedict, J. H., Digestion of neutral fats by human subjects. J. Clin. Invest., 1955, 34, 685.

39. Frazer, A. C., Fat absorption in man. St. Bartholomew's Hospital Journal, 1950, 54, 27.

40. Schönheyder, F., and Volqvartz, K., The gastric lipase in man. Acta physiol. Scandinav., 1946, 11, 349.

41. Dahlqvist, A., Unpublished observation.

42. Cajori, F. A., The enzyme activity of dog's intestinal juice and its relation to intestinal digestion. Am. J. Physiol., 1933, 104, 659.

43. Heilskov, N. S. C., Studies on animal lactase. Dissertation, Copenhagen, 1956.

44. Borgström, B., The phospholipids of human bile and small intestinal content. Acta chem. Scandinav., 1957, 11, 749.

45. Lindstedt, S., The turnover of cholic acid in man. Acta physiol. Scand., 1957, 40, 1. 